Selected Papers from the 23rd International Radiocarbon Conference, Trondheim, Norway, 17-22 June, 2018 (C) 2019 by the Arizona Board of Regents on behalf of the University of Arizona. This is an Open Access article, distributed under the terms of the Creative Commons Attribution-NonCommercial-ShareAlike licence (http://creativecommons.org/licenses/by-nc-sa/4.0/), which permits non-commercial re-use, distribution, and reproduction in any medium, provided the same Creative Commons licence is included and the original work is properly cited. The written permission of Cambridge University Press must be obtained for commercial re-use.

\title{
CHRONOscope: APPLICATION FOR THE INTERACTIVE VISUALIZATION OF CARBON-14 AND BERYLLIUM-10 ATMOSPHERIC DATA
}

\author{
Andreas Neocleous*(D) - Margot Kuitems • Andrea Scifo • Michael Dee \\ Center for Isotope Research, University of Groningen, Groningen, the Netherlands
}

\begin{abstract}
Information about the global climate, the carbon cycle, changes in solar activity, and a number of other atmospheric processes are preserved in the carbon-14 and the beryllium-10 records. However, these isotope datasets are large and cumbersome to work with. We have designed a self-contained, easy-to-use application that allows for more efficient analysis of different periods and patterns of interest. For several applications in atmospheric modelling, a pre-processing stage is applied to the isotope datasets in order to interpolate the data and mitigate their low temporal resolution. In CHRONOscope, we included linear and nonlinear methods of interpolation with interactive parameter optimization. The resultant interpolated data can be extracted for further use. The main functionalities of CHRONOscope include the importation and superimposition of external data, quick navigation through the data with the use of markers, expression of the carbon-14 results in both $\Delta^{14} \mathrm{C}$ and yr BP form, separation of the data by source, and the visualization of associated error bars. We make this free software available in standalone applications for both Windows and Mac operating systems.
\end{abstract}

KEYWORDS: carbon-14, beryllium-10, data visualization, data interpolation.

\section{INTRODUCTION}

Measurements of carbon-14 $\left({ }^{14} \mathrm{C}\right.$, or radiocarbon) are primarily made for the age estimation of archaeological objects, such as wood, bones and shells. Currently, the most comprehensive dataset of atmospheric ${ }^{14} \mathrm{C}$ measurements is the IntCal13 Reimer et al. (2013) which comprises measurements of carbon-14 in known-age tree-rings over the Holocene and varved lake sediments during earlier periods. This dataset underpins the calibration of radiocarbon dates on materials of unknown age. However, using these data, researchers also investigate several solar processes, such as the periodicity of solar activity, Miyake Events, and atmospheric responses to environmental events. Another cosmogenic isotope that is used for similar tasks is beryllium-10 $\left({ }^{10} \mathrm{Be}\right)$, which is preserved in polar and high-altitude ice-cores.

Graphical interfaces are useful tools for several tasks such as data visualization and processing. In the literature, one can find interesting applications in environmental science for modelling, prediction, visualization and analysis of different data (Finkel and Nishiizumi (1997); Horiuchi et al. (2008); Berggren et al. (2009); Delaygue and Bard (2011); Heikkilä and Smith (2012); Pedro et al. (2012); Hu et al. (2015); Arundel et al. (2016); Rolph et al. (2017); Hossard et al. (2017); Arvesen et al. (2018)).

In this paper, we present an interface for visualization of the atmospheric IntCal13 dataset, for both the raw (individual laboratory) and modelled (consensus) data, and functions for processing and analyzing such as linear and non-linear data interpolation. In addition, we

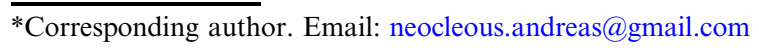


include ${ }^{10} \mathrm{Be}$ data, obtained from two key ice-core records, the NGRIP core in Greenland (Berggren et al. (2009)) and Dome Fuji, Antarctica (Horiuchi et al. (2008)). This software is available on the website of our ERC research project ${ }^{1}$.

\section{SOFTWARE AVAILABILITY}

Name of software: CHRONOscope

Developer: Andreas Neocleous

Contact Address: Center for Isotope Research, University of Groningen, Groningen, the Netherlands.

Email: neocleous.andreas@gmail.com

Link: https://www.rug.nl/research/esrig/echoes/chronoscope

Program Language: MATLAB

Year first official release: 2018

License: Free for non-commercial use.

\section{SOFTWARE FUNCTIONALITY}

\section{Overview}

The proposed software illustrates atmospheric data from available datasets and allows for interactive and detailed visualization of radiocarbon $\left({ }^{14} \mathrm{C}\right)$, Delta carbon-14 $\left(\Delta^{14} \mathrm{C}\right)$ and beryllium-10 $\left({ }^{10} \mathrm{Be}\right)$. Navigation between different dates is easily achieved with the use of markers or by manual set-up of desired dates. A function for linear and nonlinear interpolation of the data is embedded and the new data can be exported in Microsoft Excel format. Finally, external data can be imported and superimposed on the existing ones.

\section{Figure Tools}

At the top of the application we introduce a number of plot tools that are the default for MATLAB figures. Using these, one can save the whole graph as a figure, zoom in or out, manually move the plot right or left, view particular data points and annotate data points.

\section{Navigation}

In the "navigation" panel, there are three edit boxes and two pushbuttons below every edit box. In the first two edit boxes, the user can set the date limits of the x-axis, and in the pushbuttons below, the user can select either Before Common Era (BCE) or Common Era $(\mathrm{CE})$. In the third edit box, the user can add a locator (shown as a red vertical line in Figure 1). Below the pushbuttons, there is a radiobutton that centers the plot around the locator. The range of years that are encompassed is a parameter (default $=100$ years) that can be set in the edit box next to the radiobutton. Finally, the "refresh" button will bring the figure back to the initial range.

\section{Data Types}

On the top right side of the application, we introduce five radiobuttons. The user can use these to navigate between the three data types: ${ }^{14} \mathrm{C}$ ( $\left.\mathrm{yr} \mathrm{BP}\right), \Delta^{14} \mathrm{C}(\%)$ and ${ }^{10} \mathrm{Be}$ $\left(\mathrm{X} 10^{3}\right.$ atoms $/ \mathrm{g}$ or $\mathrm{X} 10^{4}$ atoms $/ \mathrm{g}$ or $\mathrm{X} 10^{5}$ atoms $/ \mathrm{cm}^{2} /$ year (flux)). The "link" radiobutton

\footnotetext{
$\overline{{ }^{1} \text { https://www.rug.nl/research/esrig/echoes/chronoscope }}$
} 


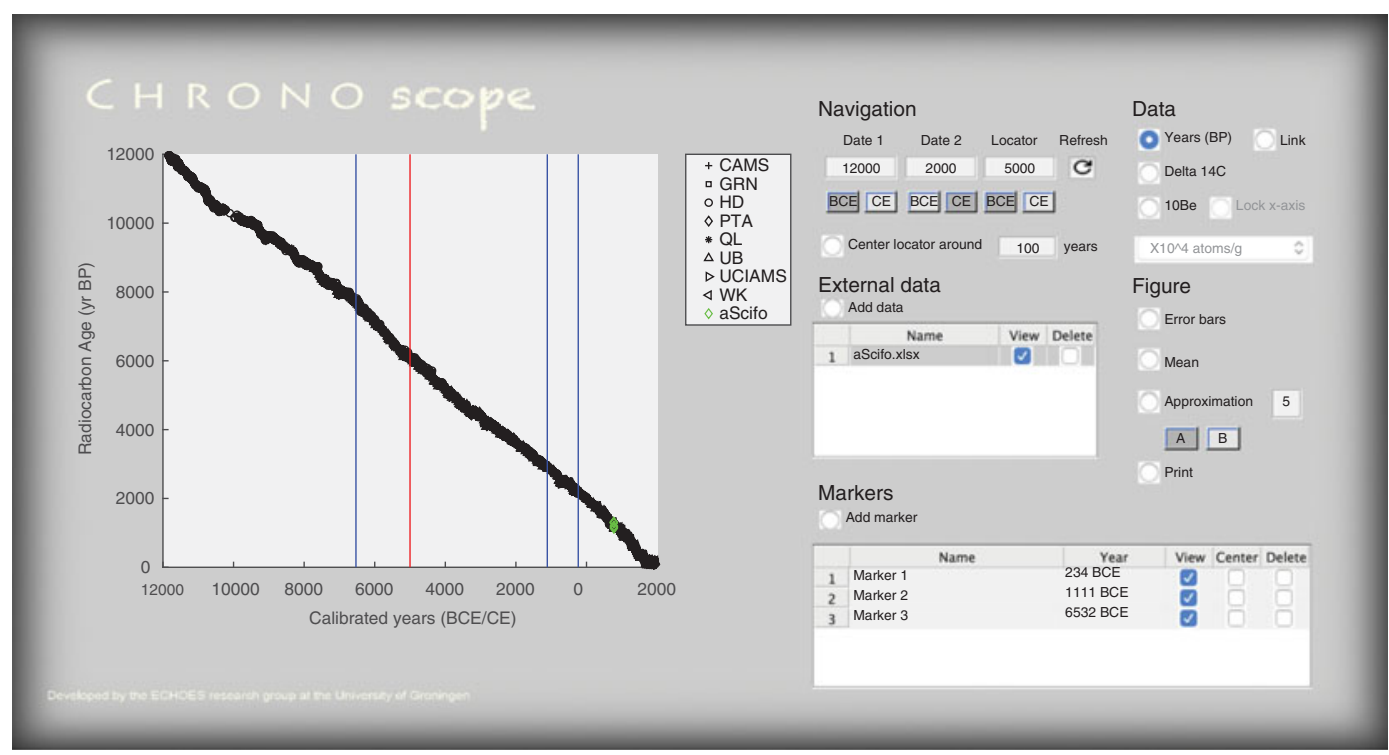

Figure 1 Software interface.

will plot the two data types of ${ }^{14} \mathrm{C}$ and $\Delta^{14} \mathrm{C}$ in a subplot. The legend of the ${ }^{10} \mathrm{Be}$, is interactive. All the data types that are illustrated can be selected or de-selected with a mouse click on their name in the legend. The ones that are de-selected are not shown in the figure. The x-axis can stay at its current limits by choosing the "Lock x-axis" radiobutton on the right. If this button is de-selected, the axis will be rescaled to the new range of the data that are plotted.

\section{Data Processing and Visualization}

The radiocarbon data typically have a $1 \sigma$ uncertainty expressed around each value (y-axis). The sample frequency (x-axis) is usually between 5 and 10 years, and on some occasions interpolation is needed. Another particularity of these datasets is that for the same years there are sometimes multiple values. This is because measurements are done by several laboratories that use trees from different parts of the world.

In CHRONOscope, in the "Figure" panel, one can visualize the uncertainty in the data by setting the "Error bars" radiobutton to "true" mode. In the same panel, we introduce the functions "Mean" and "Approximation". The functions interpolate the data linearly and non-linearly, respectively. One example of how the error bars and the approximations are shown in the application is illustrated in Figure 2. We call the linear interpolation "Mean" because before the interpolation, we compute an average between the highest and the lowest error values of the respective highest and the lowest data points, where multiple values occur. In the "Approximation" function we apply the "spline" non-linear interpolation method Reinsch (1967). We provide the option for the user to set some interpolation parameters manually, such as the number of breaks (resolution) that are used by the spline, and which data points are to be considered by the method. In the "Figure" panel below the "Approximation", we provide two options for the number of data points to be approximated. In option " $A$ " we consider the entire dataset, while in option " $B$ " we consider only the ones that are shown in the plot. 
Table 1 Example on how the data should be ordered in the Microsoft Excel file for importing them to the CHRONOscope. These data have been acquired in the Center for Isotope Research at the University of Groningen.

\begin{tabular}{lccc}
\hline (x-axis) Age CE & $\begin{array}{c}\text { (y-axis) Age } \\
\left({ }^{14} \text { C years BP }\right)\end{array}$ & error + Age plus & error - Age min \\
\hline 771 & 1311.5 & 15 & 15 \\
772 & 1295.2 & 15 & 15 \\
773 & 1315.4 & 15 & 15 \\
774 & 1282.9 & 15 & 15 \\
775 & 1203.4 & 15 & 15 \\
776 & 1127.3 & 15 & 15 \\
777 & 1163.4 & 15 & 15 \\
778 & 1172.0 & 15 & 15 \\
779 & 1172.2 & 15 & 15 \\
\hline
\end{tabular}

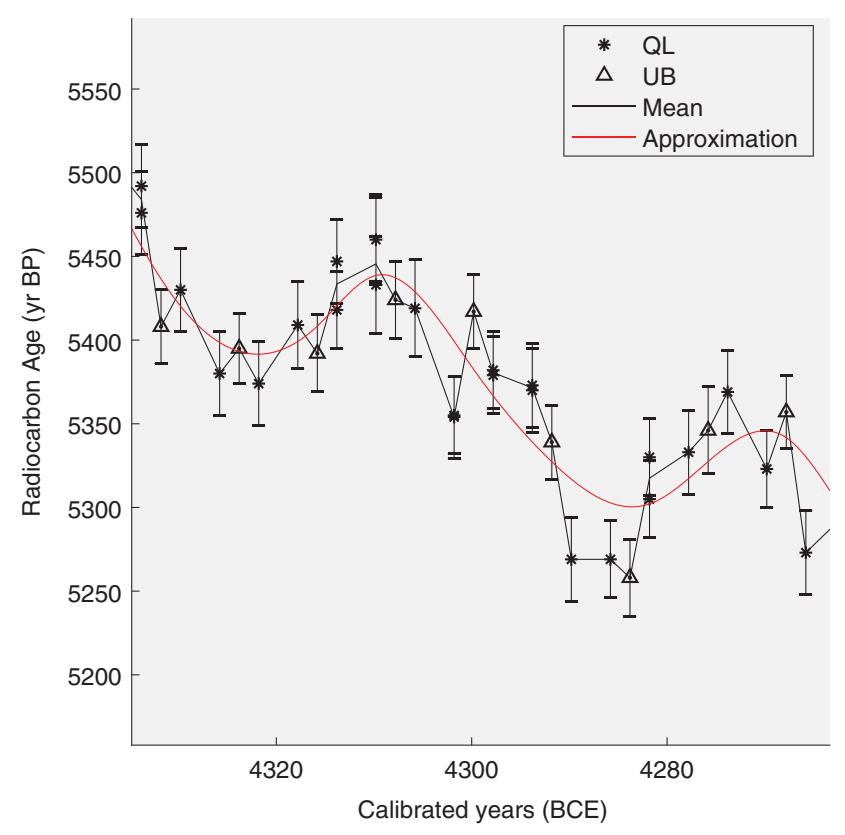

Figure 2 Example of how the error bars and the approximations are shown in the interface.

In this panel there is an option to print the current plot in an external figure and to save the plot in any available MATLAB graphics format.

\section{External Data}

In the "External data" panel, the user can import other data of their own. These data have to be in Microsoft Excel format and are uploaded from the menu (File / Import / Data). The data in the Microsoft Excel file should have the form described in the example shown in Table 1. 
The data here have been acquired by the Center for Isotope Research in the University of Groningen, Scifo (2017).

A list of external data is shown in the same panel, where the user has the option to superimpose them on IntCal13 or to remove them entirely.

The data that are shown in the figure, including the interpolations, can be exported using File / Export / Data. They will be saved in Microsoft Excel format.

\section{Markers}

In the "Markers" panel, one can add markers for quick navigation between data of interest. The markers are shown in the Figure panel as vertical blue lines. A list of markers is shown in the same panel and the user can navigate between them by choosing the respective buttons on this list. The list of markers can be exported using File / Export / Markers.

\section{CONCLUSIONS}

CHRONOscope is a useful tool for the visualization and processing of atmospheric ${ }^{14} \mathrm{C}, \Delta{ }^{14} \mathrm{C}$ and ${ }^{10} \mathrm{Be}$ data and it can be used in a wide range of analyses.

\section{ACKNOWLEDGMENTS}

This work is funded by an ERC research project (ECHOES) with grant number 714679 .

\section{REFERENCES}

Arundel J, Winter S, Gui G, Keatley M. 2016. A web-based application for beekeepers to visualise patterns of growth in floral resources using MODIS data. Environmental Modelling \& Software 83:116-125.

Arvesen A, Luderer G, Pehl M, Bodirsky BL, Hertwich EG. 2018. Deriving life cycle assessment coefficients for application in integrated assessment modelling. Environmental Modelling \& Software 99:111-125.

Berggren AM, Beer J, Possnert G, Aldahan A, Kubik P, Christl M, Johnsen SJ, Abreu J, Vinther B. 2009. A 600-year annual ${ }^{10}$ be record from the NGRIP ice core, Greenland. Geophysical Research Letters 36(11):L11801.

Delaygue G, Bard E. 2011. An Antarctic view of Beryllium-10 and solar activity for the past millennium. Climate Dynamics 36(11-12): 2201-2218.

Finkel R, Nishiizumi K. 1997. Beryllium 10 concentrations in the Greenland Ice Sheet Project 2 ice core from 3-40 ka. Journal of Geophysical Research: Oceans 102(C12):26699-26706.

Heikkilä U, Smith A. 2012. Influence of model resolution on the atmospheric transport of ${ }^{10} \mathrm{be}$. Atmospheric Chemistry and Physics 12(21): 10601-10612.
Horiuchi K, Uchida T, Sakamoto Y, Ohta A, Matsuzaki H, Shibata Y, Motoyama H. 2008. Ice core record of ${ }^{10}$ be over the past millennium from Dome Fuji, Antarctica: A new proxy record of past solar activity and a powerful tool for stratigraphic dating. Quaternary Geochronology 3(3): 253-261.

Hossard L, Bregaglio S, Philibert A, Ruget F, Resmond R, Cappelli G, Delmotte S. 2017. A web application to facilitate crop model comparison in ensemble studies. Environmental Modelling \& Software 97:259-270.

$\mathrm{Hu}$ Y, Cai X, DuPont B. 2015. Design of a web-based application of the coupled multi-agent system model and environmental model for watershed management analysis using Hadoop. Environmental Modelling \& Software 70: $149-162$.

Pedro JB, McConnell JR, van Ommen TD, Fink D, Curran MA, Smith AM, Simon KJ, Moy AD, Das SB 2012. Solar and climate influences on ice core ${ }^{10}$ be records from Antarctica and Greenland during the neutron monitor era. Earth and Planetary Science Letters 55:174-186. 
Reimer PJ, Bard E, Bayliss A, Beck JW, Blackwell PG, Ramsey CB, Buck CE, Cheng $\mathrm{H}$, Edwards RL, Friedrich M et al. 2013. IntCal13 and Marine13 radiocarbon age calibration curves $0-50,000$ years cal BP. Radiocarbon 55(4):1869-1887.

Reinsch CH. 1967. Smoothing by spline functions. Numerische mathematik 10(3): 177-183.
Rolph G, Stein A, Stunder B. 2017. Real-time environmental applications and display system: Ready. Environmental Modelling \& Software 95:210-228.

Scifo A. 2017. The Radiocarbon Signature of Past Radiation Events. Master's thesis Rijksuniversiteit Groningen the Netherlands. 